\title{
The Life Cycle Environmental Performance of On-Site or Decentralised Wastewater Treatment Systems for Domestic Homes
}

\author{
John Gallagher*(D) and Laurence W. Gill (D) \\ Department of Civil, Structural \& Environmental Engineering, Trinity College Dublin, University of Dublin, \\ D02 PN40 Dublin, Ireland; Laurence.gill@tcd.ie \\ * Correspondence: j.gallagher@tcd.ie
}

Citation: Gallagher, J.; Gill, L.W. The Life Cycle Environmental

Performance of On-Site or

Decentralised Wastewater Treatment Systems for Domestic Homes. Water 2021, 13, 2542. https://doi.org/ $10.3390 /$ w13182542

Academic Editor: Sathaa Sathasivan

Received: 16 July 2021

Accepted: 14 September 2021

Published: 16 September 2021

Corrected: 17 January 2022

Publisher's Note: MDPI stays neutral with regard to jurisdictional claims in published maps and institutional affiliations.

Copyright: (c) 2021 by the authors. Licensee MDPI, Basel, Switzerland. This article is an open access article distributed under the terms and conditions of the Creative Commons Attribution (CC BY) license (https:/ / creativecommons.org/licenses/by/ $4.0 /)$.

\begin{abstract}
There is little knowledge regarding the environmental sustainability of domestic onsite or decentralised wastewater treatment systems (DWWTS). This study evaluated six unique life cycle environmental impacts for different DWTTS configurations of five conventional septic tank systems, four packaged treatment units, and a willow evapotranspiration system. Similar freshwater eutrophication (FE), dissipated water (DW), and mineral and metal (MM), burdens were noted between the packaged and conventional system configurations, with the packaged systems demonstrating significantly higher impacts of between $18 \%$ and $56 \%$ for climate change (CC), marine eutrophication (ME), and fossils (F). At a system level, higher impacts were observed in systems requiring (i) three vs. two engineered treatment stages, (ii) a larger soil percolation trench area, and (iii) pumping of effluent. The evapotranspiration system presented the smallest total environmental impacts (3.0-10.8 lower), with net benefits for FE, ME, and MM identified due to the biomass (wood) production offsetting these burdens. Further analysis highlighted the sensitivity of results to biomass yield, operational demands (desludging or pumping energy demands), and embodied materials, with less significant impacts for replacing mechanical components, i.e., pumps. The findings highlighted the variation in environmental performance of different DWTTS configurations and indicated opportunities for design improvements to reduce their life cycle impacts.
\end{abstract}

Keywords: environmental impacts; wastewater treatment; treatment processes; evapotranspiration

\section{Introduction}

The treatment of wastewater is a vital process for environmental protection and returning treated effluent to the water cycle [1], as well as for the protection of public health. The energy demands associated with wastewater treatment systems (WWTSs) represent $1 \%$ of total global electricity, or $25 \%$ of overall water and wastewater energy demands [2]. Moreover, as the urban wastewater treatment directive (91/271/EEC) undergoes a review in 2020/2021 [3], the potential for enhanced treatment standards relating to WWTSs will very likely translate as increases to the energy requirements for wastewater treatment [2].

In recent years, large-scale infrastructure networks have come under increasing scrutiny with respect to their social, economic, and environmental sustainability, with studies making comparisons between centralised and decentralised water infrastructure [4-6]. In this context, the conception and evaluation of water infrastructure has evolved from a technical focus to a more sociotechnical focus, taking into account contemporary changes in society, technology, and nature [7]. With this, there has been an increased interest in the sustainability of decentralised water and wastewater infrastructure systems, alongside advancements in treatment technology to protect environmental pollution [8-11]. Decentralised or on-site systems are of particular interest and value in rural environments [10,12]. Ireland represents one of a small number of European countries where less than $80 \%$ of the population is connected to centralised or urban WWTSs [1], with more than 
one third of households depending on on-site or domestic wastewater treatment systems (DWWTSs) for their effluent disposal [13]. In low- and middle-income countries, the proportion of the population using these systems is significantly higher and estimated to provide improved sanitation for up to $64 \%$ of the population [14]. Moreover, with an ever-growing global population, predominantly in areas currently unserved by centralised wastewater treatment solutions, it is likely that such small-scale, on-site technologies will form sanitation solutions for many more people in the world over the coming years. These DWWTSs are engineered systems that offer bespoke technological solutions that take into account local on-site conditions (soil type, depth and permeability, topography, underlying aquifers, etc.) with the aim to protect both groundwater and surface water resources [15]. Many systems act as passive treatment systems relying on a combination of a septic tank and soil treatment systems (i.e., percolation area) [16,17]. In circumstances where soil conditions are not adequate for secondary or tertiary treatment, more advanced effluent treatment is required prior to discharge to the ground via small packaged aerobic treatment units or processes constructed on site such as sand filters or constructed wetlands [18-20].

Whilst there is a requirement for energy in water and wastewater treatment and supply in decentralised settings [21,22], there is often a case for it as the preferred option to centralised management. Small clustered decentralised systems present an economically and environmentally viable solution for WWTS, although they often face management and legal barriers if they are to operate effectively; equally, domestic-scale on-site WWTSs have low construction and operational costs [23]. Hence, technical innovation; environmental regulation; and concerns for sustainability, adaptability, and affordability are gradually shifting the focus back towards decentralized and on-site water systems [24].

Life cycle assessment (LCA) and life cycle costing (LCC) can provide insights into the environmental and economic performance of WWTSs [25] and can subsequently inform decision making in the design and selection of specific treatment processes. This can be the case from both an embodied and an operational perspective, as centralised WWTSs present larger contributions to greenhouse gas (GHG) emissions compared to domestic scale systems [26]. This is attributed to the large quantities of embodied materials used in advanced treatment technologies and the operational energy demands of wastewater treatment processes. However, opportunities for energy recovery in the form of biogas and heat recovery offset the energy and associated carbon requirements of WWTSs [26-29]. Studies by Niero and Pizzol [28] and McNamara and Horrigan [29] compared the life cycle performance of different WWTSs and considered eight to nine different environmental impact categories; yet variations in the operational life cycle, the scale of the system, and the offset due to anaerobic digestion influenced these results.

A greater research focus for LCAs of wastewater has been on centralised WWTSs or scaled decentralised systems. Nogueira and Brito [30] demonstrated the value of LCA in identifying opportunities for environmental savings through design changes to change materials (steel to high-density polyethylene) and operations (extended design lifetime). Understanding the life cycle operational demands and embodied impacts is very important in the design of WWTS [31]. The results from an LCA of a wastewater system can identify the specific impact categories most affected by the system or can help determine the impacts of designing a passive system with zero operational energy burdens $[32,33]$. An LCA investigation of wastewater can provide a range of unique insights that add value in the design and selection process, whether related to performance, e.g., nitrogen removal in constructed wetlands [33]; added value, e.g., the suitability of treatment for water reuse [31]; or balancing economic and environmental considerations, e.g., changing materials in design or extending process lifespans [30]. This LCA study focused on comparing the environmental performance of different DWWTSs as a whole and at a single household scale, given their prevalence in the world. The results can be used to provide insights and guidance with respect to the design of different configurations of such on-site systems, particularly from a longer-term sustainability perspective. 


\section{Methods}

\subsection{Goal and Scope}

This study applied LCA methodology to quantify the environmental burdens associated with the embodied and operational phases of different treatment processes adopted within a range of different DWWTSs. These different treatment configurations present a broad range of options that might need to be considered depending on local site conditions, in particular those linked to the percolation characteristics and the depth of the soil into which the effluent is discharged. This includes more conventional designs involving a septic tank (primary treatment) and percolation area (combined secondary and tertiary treatment), with small-scale packaged secondary treatment plants and biomass-producing (willow) evapotranspiration treatment systems. The environmental performance of these domestic-scale systems was examined as a range of configurations of primary, secondary, and/or tertiary treatment processes. In addition, an uncertainty and sensitivity analysis examined factors that may influence the environmental performance of these systems.

The LCA of these DWWTSs was conducted in accordance with ISO 14040 and 14044 guidelines [34,35]. When applied, the functional unit chosen in this study was the influent produced by a one-person equivalent (p.e.), a suitable metric where uncertainty exists for flow data through the system [36]. An attributional approach was followed to quantify the impacts of each DWWTS configuration.

Data for the construction and operation phases were obtained through design drawings and best-practice guidelines for DWWTS (e.g., EPA [37]), site data from ongoing research of domestic-scale treatment systems, and specifications from suppliers for components, e.g., pumps and prefabricated tanks. Details relating to transportation, processing raw materials to manufacture DWWTS products, and construction/installation burdens were accounted for in the analysis. In addition, a lifespan of 30 years was selected for the operational stage of the DWWTS's life cycle as it represented the lifespan of the packaged treatment processes examined in this study. It should be noted that the end-of-life stage was omitted from the assessment as it presented too many unknowns regarding the decommissioning of this type of system. Additionally, the direct emissions of greenhouse gases (carbon dioxide, methane, and nitrous oxide) from the different treatment configurations during their operation was not included as this is a subject that has received very little research to date $[38,39]$ and so lacks reliable estimates that can be used.

The life cycle impact assessment (LCIA) will quantify the contribution analysis results and illustrate the environmental burdens of the different primary, secondary, and tertiary treatment systems in each DWWTS configuration. This will provide an insight into the specific stages and types of treatment processes that present high environmental burdens during their installation and operation. A subsequent sensitivity analysis will consider measures to reduce the associated environmental burdens of each on-site system configuration. This will also take into consideration the impact of water efficiency in domestic settings, which reduces the quantity of influent and therefore translates to a reduction in the size of the current systems.

\section{Decentralised Wastewater Treatment Systems}

The ten on-site configurations for DWWTS are presented in Figure 1 and Table 1. These systems represent the range of conventional and more advanced single-house treatment options that could arise in Ireland following a site assessment procedure according to the Environmental Protection Agency's Code of Practice for Domestic Waste Water Treatment Systems (Population Equivalent $\leq 10$ ) [37]. The systems represent several parallel generic designs with a 4-person population equivalent (p.e.) capacity that were developed for the LCA. The majority of domestic homes in Ireland with DWWTSs have septic tank and percolation areas, of which a 4-person p.e. capacity represents a common household size for these systems. The majority of the remaining $20 \%$ using packaged plants. The evapotranspiration (willow) system is a new form of treatment system recently added to the EPA's code of practice, with only experimental sites in existence until now. 
(a)

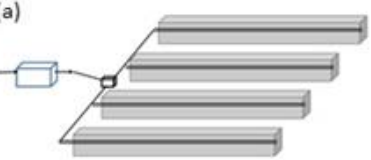

(c)

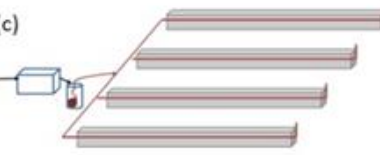

(e)

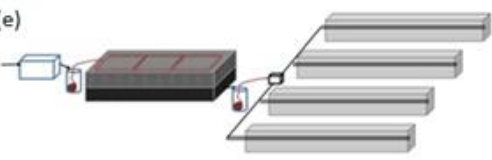

(d) (b)
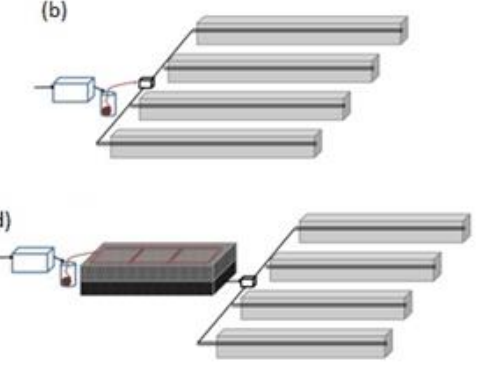

(f)

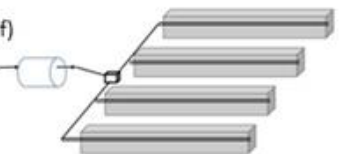

(s)
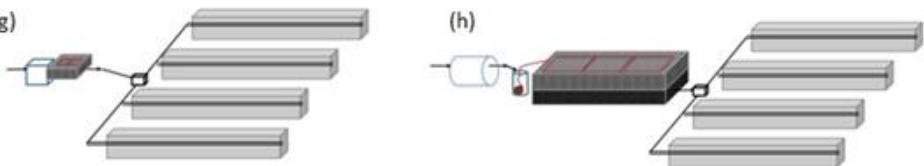

(i)
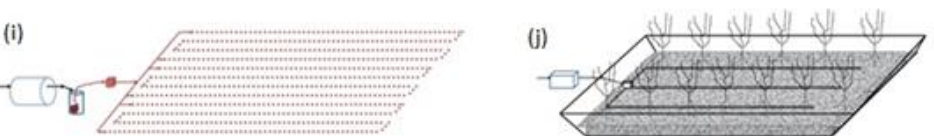

Figure 1. Schematic diagrams of the 10 different configurations of DWWTS as outlined in Table 1 (additional details provided in treatment process descriptions in Table A1 in Appendix A).

Table 1. Details of the ten different DWWTS configurations examined in this study (each design assumes four full-time occupants each producing $150 \mathrm{~L}$ of effluent per day).

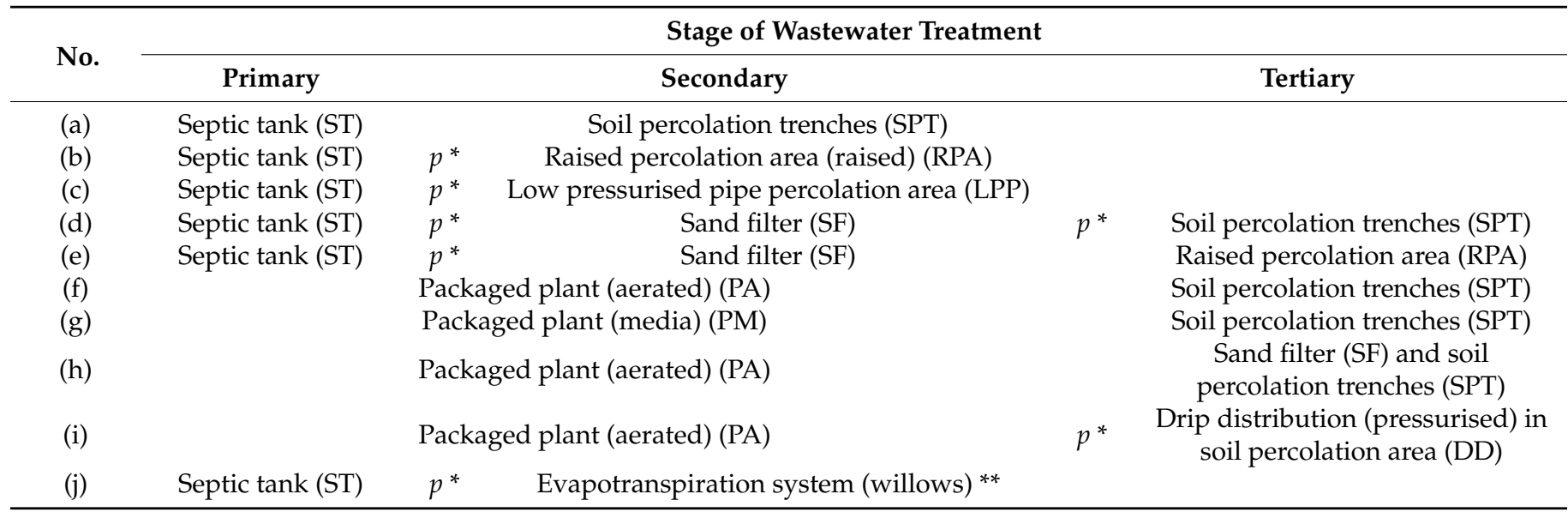

${ }^{*} p$ refers to pumping requirements into treatment stage; ${ }^{* *}$ Willow evapotranspiration system designed for 100 litres of effluent per person per day.

The 10 systems present different levels of treatment (primary, secondary, and tertiary) before discharge to final soil percolation to groundwater. Summary descriptions of each treatment process are provided in Table A1 in Appendix A. In this analysis it was assumed that direct surface water discharge is not allowed, and so it was not considered. The first three systems $(\mathrm{a}-\mathrm{c})$ represent the most conventional forms of on-site treatment, involving a septic tank with different methods of distributing the effluent to a soil percolation area (depending on local site conditions). Systems (d) and (e) also incorporate a sand filter constructed on site as a form of secondary treatment before the effluent is discharged to the percolation area. The subsequent four systems $(\mathrm{f}-\mathrm{i})$ incorporate mechanically aerated 
packaged treatment plants with different methods of effluent distribution. Finally, system (j) is a willow evapotranspiration treatment system that produces biomass as part of the treatment process, which is a relatively new system that is suitable for areas of low soil permeability as it significantly reduces any effluent discharge to the soil [40].

Each DWWTS was designed on the basis that four full-time occupants are considered in the house as each producing an average of 150 litres of effluent per day, as per the Irish EPA standards [37]. It was assumed that the soil is suitable for the discharge of final respective effluents from the different design configurations.

\subsection{Life Cycle Inventory Database}

Primary inventory data related to the different treatment systems are provided in Table A2 in Appendix A. The boundary conditions applied in this study accounted for all embodied and operational requirements to ensure the systems could operate effectively for a period of 30 years. An overview of the key inventory data in relation to the embodied burdens and operation of these treatment systems are presented in Table 2.

The Ecoinvent v.3.6 database provided all the environmental impact data for all materials and manufacturing processes of products [41,42].

Table 2. Key inventory data and associated details or assumptions taken as part of the LCA process for the DWWTS.

\begin{tabular}{|c|c|}
\hline Item & Details or Assumptions \\
\hline $\begin{array}{l}\text { Embodied burdens of } \\
\text { on-site systems }\end{array}$ & $\begin{array}{l}\text { Material quantities and manufacturing processes derived from design guidance drawings and } \\
\text { product specifications. } \\
\text { Transportation of all raw materials, treatment system components, and maintenance travel to site } \\
\text { assumed to equal } 50 \mathrm{~km} \text { for all activities. } \\
\begin{array}{c}\text { Duration of time hydraulic digger for on-site construction was translated into volume of material } \\
\text { excavated or moved. Assumption that all material was distributed around site and not removed } \\
\text { from site. }\end{array}\end{array}$ \\
\hline Operational demands & $\begin{array}{l}\text { Desludging of septic tank and aerated/media settlement tank every four and one years, respectively [43]. } \\
\text { Lifespan of pumps in on-site systems is less than 30-year operational lifespan examined and thus } \\
\text { replaced every } 5 \text { years. } \\
\text { Decarbonisation of the electricity grid to be accounted for when calculating energy demands; therefore, } \\
\text { environmental impacts of future electricity were accounted for based on predictions outlined in [44]. }\end{array}$ \\
\hline
\end{tabular}

\subsection{Selection of Impact Categories}

Prior to quantifying the potential environmental impacts of the on-site schemes, LCIA impact categories were selected. The International Life Cycle Data (ICLD) system was selected as the appropriate method to assess the key environmental impacts associated with the DWWTS [42]. The following six impact categories were chosen from the LCIA 2.0 midpoint method: climate change total (CC), freshwater eutrophication (FE), marine eutrophication (ME), dissipated water (DW), fossils (F), and minerals and metals (MM). The midpoint method was chosen as it minimises uncertainty and is preferred in studies relating to wastewater. The six impact categories were selected as they capture a combination of embodied and operational impacts on the climate, the ecosystem, and resources.

The purpose of applying LCA in the comparison of these DWWTS was to provide insights into the potential for enhancing the sustainable design of these treatment processes. It is important to consider the capacity for any engineered system, regardless of function or scale, to identify opportunities to reduce its associated embodied and operational impacts over its life cycle. Therefore, the findings from this LCA have the scope to inform more environmentally conscious design, construction, and operation of DWWTS.

The boundary conditions and impact categories chosen in this study aimed to effectively capture the more appropriate impacts of on-site treatment systems on climate change, ecosystem quality, and resources. However, within the constraints of this study it is acknowledged that a DWWTS may have an operational lifespan greater than 30 years, and the selection of specific impact categories could have been expanded further to include 
human health impacts or additional burdens associated with climate, the natural ecosystem, and resources depletion.

\subsection{Interpretation and Analyses of LCA Results}

The impact assessment of the different on-site configurations for the ten DWWTSs were compared for the six impact categories, considering the embodied and operational demands of each treatment system. This provided an insight into the performance, in terms of material contributions and associated burdens between the different on-site treatment systems.

The results are initially presented as cumulative burdens, with a further breakdown of embodied and operational impacts for different treatment processes in each configuration. Graphical representations of environmental impacts relating to the embodied and operational burdens of the primary, secondary, and tertiary treatment processes are presented. In addition, the results outline the impacts associated with specific materials in each DWWTS configuration.

\section{Uncertainty and Sensitivity Analysis}

An uncertainty analysis was conducted to calculate the environmental impacts of potential modifications to these treatment systems during their construction. Furthermore, the sensitivity analysis examined the robustness of the LCA results, quantifying the margin of error relating to the construction and operation of these systems. Table 3 presents the scenarios considered as part of the uncertainty and sensitivity analysis relating to the environmental performance of the DWWTSs.

Table 3. Scenarios of uncertainty and sensitivity of construction and operational burdens of DWWTS.

\begin{tabular}{|c|c|c|}
\hline & Scenario & Reason and Condition Considered for Proposed Scenario \\
\hline Uncertainty & Use of plastic or concrete septic tank & $\begin{array}{l}\text { The use of a conventional concrete septic tank as opposed to a } \\
\text { modern prefabricated plastic septic tank. }\end{array}$ \\
\hline \multirow[t]{4}{*}{ Sensitivity } & $\begin{array}{l}\text { Desludging of septic/settlement tanks } \\
\text { more frequently }\end{array}$ & $\begin{array}{l}\text { Requirement to empty septic tank and aerated system tanks may } \\
\text { need to occur } 10 \%, 25 \% \text {, or } 50 \% \text { more regularly than the } \\
\text { recommended } 4 \text { - and 1-year durations, respectively. }\end{array}$ \\
\hline & $\begin{array}{l}\text { Pumps requiring replacement more } \\
\text { frequently }\end{array}$ & $\begin{array}{c}\text { Submersible pumps need to be replaced } 10 \%, 25 \% \text {, or } 50 \% \text { earlier } \\
\text { than their proposed design life of } 5 \text { years. }\end{array}$ \\
\hline & $\begin{array}{l}\text { Operational energy demands more than } \\
\text { originally estimated }\end{array}$ & $\begin{array}{l}\text { Operational energy demands for pumping and aeration is } \\
\text { under-estimated by } 10 \%, 25 \% \text {, or } 50 \% \text { in each treatment system. }\end{array}$ \\
\hline & Reduced yield of biomass production & $\begin{array}{c}\text { A reduction in biomass production of } 10 \%, 25 \% \text {, or } 50 \% \text { as yield is } \\
\text { affected by a range of growth factors. }\end{array}$ \\
\hline
\end{tabular}

The choice of materials used in the septic tank represents a shift in the preferred option of a prefabricated plastic septic tank and the uncertainty as to the impacts of this change on the environmental burdens of DWTTS. The systems were designed for a 4person household; however, excess use may impact the requirement for more frequent desludging, energy demands, and a reduction in pumping lifespans. Therefore, these three conditions were examined with a $10 \%, 25 \%$, and $50 \%$ level of uncertainty to represent a low, medium, and high risk of increased environmental burdens. Lastly, the production of biomass depends on environmental conditions in addition to effluent input; as such, the $10 \%, 25 \%$, and $50 \%$ represented similar low, medium, and high knock-on impacts on the environmental performance of this process for the evapotranspiration treatment system.

\section{Results and Discussion}

\subsection{Cumulative Environmental Impacts of DWTTS}

The cumulative burdens for all DWWTSs are presented in Table 4. The results demonstrate the variability in results across the different environmental burden categories con- 
sidered for each decentralised treatment system over their 30-year operational lifespan. The treatment system configurations involving septic tanks (a-e) compared to packaged treatment systems (f-i) presented mixed results, which made both sets of DWWTSs difficult to distinguish across these categories. However, in general, the on-site packaged treatment systems presented greater environmental burdens than the conventional systems.

Table 4. Cumulative environmental burdens per population equivalent (p.e.) for each DWWTS during its construction and operation life cycle.

\begin{tabular}{ccccccc}
\hline & \multicolumn{2}{c}{ Climate Change } & \multicolumn{2}{c}{ Ecosystem Quality } & \multicolumn{2}{c}{ Resources } \\
\cline { 2 - 7 } DWWTS & $\begin{array}{c}\text { CC } \\
\text { (kg CO } \mathbf{~} \text { eq./p.e.) }\end{array}$ & $\begin{array}{c}\text { FE } \\
\text { (kg P-eq./p.e.) }\end{array}$ & $\begin{array}{c}\text { DW } \\
\mathbf{( m}^{\mathbf{3}} \text { water eq./p.e.) }\end{array}$ & $\begin{array}{c}\text { ME } \\
\text { (kg N-eq./p.e.) }\end{array}$ & $\begin{array}{c}\text { F } \\
\text { (MJ/p.e.) }\end{array}$ & $\begin{array}{c}\text { MM } \\
\text { (kg Sb eq./p.e.) }\end{array}$ \\
\hline (a) ST-SPT & 926.3 & 0.35 & 0.93 & 429.5 & 21,827 & $2.64 \times 10^{-2}$ \\
(b) ST-RPA & 1.164 .8 & 0.42 & 1.30 & 480.6 & 25,246 & $3.12 \times 10^{-2}$ \\
(c) ST-LPP & 752.5 & 0.25 & 0.93 & 245.6 & 15,070 & $1.60 \times 10^{-2}$ \\
(d) ST-SF-SPT & 1.478 .8 & 0.53 & 1.78 & 633.7 & 30,106 & $4.56 \times 10^{-2}$ \\
(e) ST-SF-RPA & 926.3 & 0.35 & 0.93 & 429.4 & 21,827 & $2.64 \times 10^{-2}$ \\
(f) PAS-SPT & 1.074 .9 & 0.31 & 1.32 & 383.6 & 23,131 & $2.40 \times 10^{-2}$ \\
(g) PMS-STP & 1.650 .9 & 0.45 & 1.76 & 442.6 & 28,352 & $2.96 \times 10^{-2}$ \\
(h) PAS-SF-SPT & 1.569 .1 & 0.39 & 2.41 & 499.2 & 27,726 & $4.17 \times 10^{-2}$ \\
(i) PAS-DD-SPT & 2.108 .6 & 0.56 & 3.16 & 626.7 & 39,602 & $4.54 \times 10^{-2}$ \\
(j) ST-W & 809.8 & -1.61 & -58.98 & 2.085 .8 & 60,541 & $-4.16 \times 10^{-1}$ \\
\hline
\end{tabular}

The results ranged from a small to negligible difference of $1-7 \%$ for freshwater eutrophication (FE), dissipated water (DW), and minerals and metals (MM), e.g., 0.415 vs. $0.430 \mathrm{~kg}$ P-eq./p.e. for FE, to more substantial impacts of between $22-61 \%$ higher for climate change (CC), marine eutrophication (ME), and fossils (F), e.g., 2.16 vs. $1.34 \mathrm{~kg} \mathrm{N-q./p.e.} \mathrm{for} \mathrm{ME.} \mathrm{In}$ addition, treatment systems with three stages of engineered treatment processes presented greater burdens of between $23 \%$ and $49 \%$ than two-stage treatment systems.

A comparison on the two-stage systems with SPTs displayed a 9-32\% reduction in the embodied burdens with the packaged primary treatment, as it produced lower impacts in its manufacturing and installation than the septic tank. However, a 3.3 to 8.3 times increase in operational demands was attributed to additional pumping requirements in the advanced treatment systems. As such, the net results for these two-stage septic tank systems displayed show that the FE, DW, and MM burdens presented, on average, marginal differences for the aerated system of $6 \%$ as compared to a notable average $40 \%$ increases (ranging from $78-90 \%$ (CC and ME) to 3-12\% (DW and MM)). It outlines that the differences in the impacts of energy for pumping is unique to the embodied burdens of these treatment processes. Similarly, the requirement for a raised percolation increased the total burdens for all six impact categories, yet the largest net impact was associated with additional pumping demands. The alternative filtration processes-a low pressured pipe system, sand filters, and a drip distribution - offered a smaller area, and thus lower embodied impacts, yet a larger operational requirement to support a similar level of secondary treatment in both conventional and packaged treatment systems across each impact category.

The different configurations of primary, secondary, and tertiary treatment processes were therefore considered as the dominating factor in the overall environmental burdens attributed to each treatment system. This required design configuration is usually dictated by the on-site soil permeability and the depth of the unsaturated zone for the percolation area: soils with a deep unsaturated zone $(>1 \mathrm{~m})$ of reasonable percolation require much less up-front treatment, as the natural soil provides the final requisite levels of treatment to the effluent as it percolates through before entering the groundwater.

The final evapotranspiration treatment system (j) presented the smallest burdens for four of the six impact categories in comparison to the other DWWTSs, with three of these (FE, DW, and MM) impact categories presenting a net environmental benefit due to the production on the biomass during the operational lifespan of the system. However, the 
ME and F impacts presented significantly larger environmental burdens for the evapotranspiration systems as the construction materials (geotextiles, liners, and a large quantity of gravel) contributed to these significant impacts.

\subsection{Contribution Analysis for DWTTS}

Figure 2 provides a further breakdown for the contributions of the construction and operational impacts for the conventional and packaged treatment systems over the 30-year timeframe. Table A3 in Appendix B provides the quantitative breakdown of the embodied and operational burdens of the DWWTS. The willow-ET system is dealt with separately due to its unique capacity to produce biomass during its operational lifespan.

cc - Climate Change Total (kg CO2 eq./p.e.)

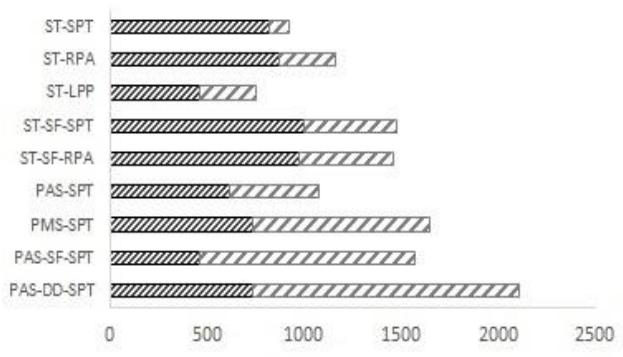

ME - Marine Eutrophication ( $\mathrm{kg} \mathrm{N}$-eq./p.e.)

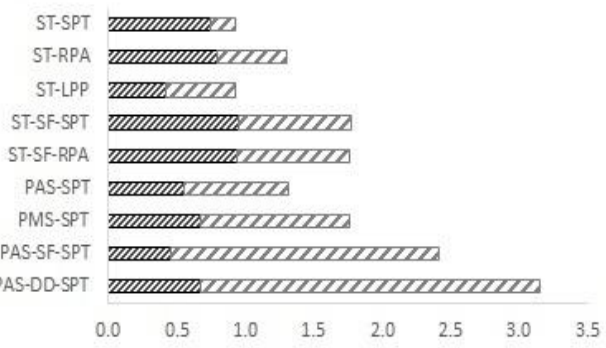

F- Fossils (MJ/p.e.)

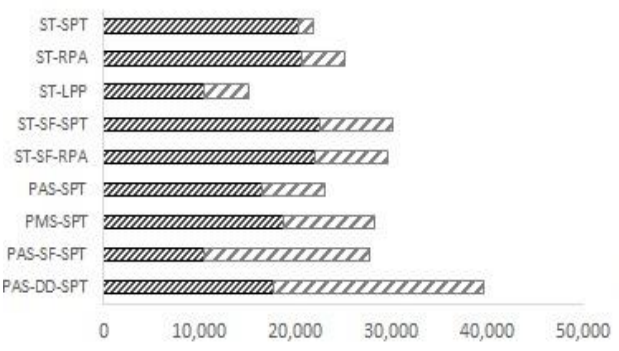

Embodied
FE-Freshwater Eutrophication (kg P-eq./p.e.)

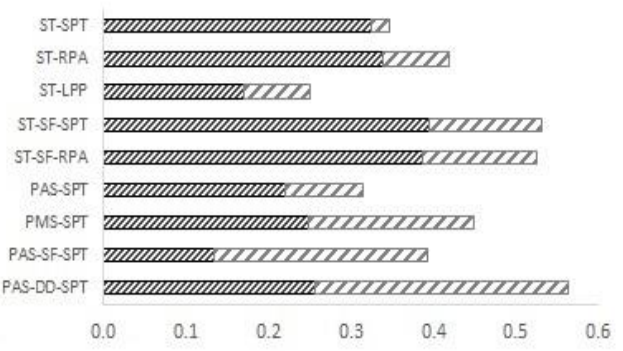

DW - Dissipated Water ( $m^{3}$ water eq./p.e.)

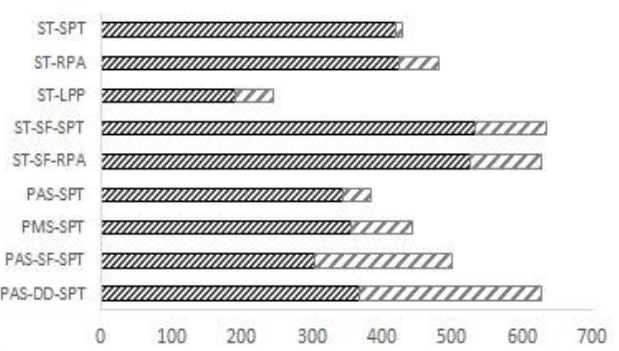

MM - Minerals and Metals (kg Sb eq./p.e.)

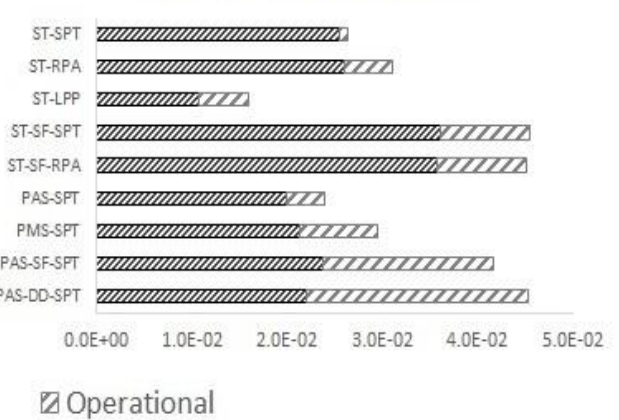

Figure 2. Breakdown of the cumulative environmental impacts for each DWTTS as embodied and operational burdens over a 30-year lifespan (Tables A4 and A5 in Appendix C provide the breakdown of embodied and operational burdens for each DWWTS).

\subsubsection{Conventional Septic Tank Systems}

As illustrated in Figure 2, the embodied and operational burdens of the conventional septic tank systems demonstrate varying impacts.

In the construction and installation of these systems, the main difference observed between the more conventional systems with septic tanks (a-e) was that the embodied impact for the low pressurised pipe (LPP) process presented much lower burdens than the other four DWWTSs using packaged treatment systems. An average of $72-92 \%$ of the total impacts were associated with the embodied impacts of these DWWTS, with the ST-LPP 
system presenting an even split between embodied and operational burdens. This was due to (i) the reduced material demands of the ST-LPP system as compared to the percolation trenches required in the other four systems, and (ii) there was no requirement for a tertiary treatment process in the two sand filter systems. In contrast, greater operational burdens were attributed to the conventional systems, which required electricity for pumping as a ST-SPT as compared to the impacts of desludging the septic tank every four years. As such, the ST-LPP system presented the lowest environmental burdens for five of the six impact categories, with the exception of the ME burden due to the contribution of pumping components and electricity demands. The requirement for three stages of treatment in the sand filter systems is reflected in the total burdens of these systems.

\subsubsection{Advanced Packaged Treatment Systems}

The four packaged treatment systems demonstrated mixed results in Table 5 as compared to conventional systems, with the difference in average total burdens ranging from $18 \%$ to $56 \%$ greater for CC, ME, and fossils $(\mathrm{F})$; yet, negligible impacts $(1-3 \%)$ were noted for FE, DW, and MM. A further examination of the embodied and operational burdens provides a clearer indication of the reasons for more substantial environmental impacts. The average embodied burdens were between $18 \%$ and $34 \%$ lower for all impact categories; yet, in contrast, the operational impacts were substantially greater in comparison to the more conventional septic tank systems (68-190\%) across the six different impact categories. On average, the packaged systems with the sand filter (PA-SF-STP) and drip distribution system (PA-DD-SPT) presented a greater operational impact than embodied burdens at $60 \%$ and $58 \%$ of the total impacts over a 30-year lifespan, respectively.

Table 5. Cumulative environmental burdens and breakdown of embodied and operational life cycle impacts per population equivalent (p.e.) for the evapotranspiration treatment system.

\begin{tabular}{|c|c|c|c|c|c|c|}
\hline \multirow[b]{2}{*}{$\begin{array}{c}\text { Life Cycle Stage } \\
\text { of Treatment }\end{array}$} & \multirow{2}{*}{$\begin{array}{c}\text { Climate Change } \\
\mathrm{CC} \\
(\mathrm{kg} \mathrm{CO} \text { eq./p.e. })^{-}\end{array}$} & \multicolumn{3}{|c|}{ Ecosystem Quality } & \multicolumn{2}{|c|}{ Resources } \\
\hline & & $\begin{array}{c}\text { FE } \\
\text { (kg P-eq./p.e.) }\end{array}$ & $\begin{array}{c}\mathrm{DW} \\
\left(\mathrm{m}^{3} \text { water eq./p.e. }\right)\end{array}$ & $\begin{array}{c}\text { ME } \\
\text { (kg N-eq./p.e.) }\end{array}$ & $\begin{array}{c}\text { F } \\
(M J / \text { p.e. })\end{array}$ & $\begin{array}{c}\text { MM } \\
\text { (kg Sb eq./p.e.) }\end{array}$ \\
\hline Embodied & 4079.6 & 1.63 & 4.45 & 2812.5 & 92,132 & $1.83 \times 10^{-1}$ \\
\hline Operational & -3.269 .8 & -3.25 & -63.43 & -726.6 & $-31,591$ & $-6.00 \times 10^{-1}$ \\
\hline Total & 809.8 & -1.61 & -58.98 & 2085.8 & 60,541 & $-4.16 \times 10^{-1}$ \\
\hline
\end{tabular}

The pumping requirements of these packaged systems were noted to be much greater than that of the conventional systems, which lead to more significant burdens. A similar outcome was observed between the conventional and advanced systems, as systems that add tertiary treatment present greater burdens for all impact categories.

\subsubsection{Evapotranspiration Treatment System}

The willow evapotranspiration treatment system (ST-W) produced distinct results (Table 5) in relation to both its embodied and operational performance.

In comparison to the conventional and packaged systems, the magnitude of the ST-W system's embodied burdens was, on average, a minimum of five times higher (ranging from 3.0-10.8 times) for all impact categories due to the large quantity of geotextiles, liner, and gravel material for the installation, as well as the energy involved in the excavation and backfilling of these large basins. More uniquely, the operational burdens for the evapotranspiration system produced a negative impact due to the production of biomass (i.e., wood) and its associated value as a resource. This presented both positive and negative net burdens for this on-site treatment system and highlights the importance of considering a range of impact categories to ensure an informed decision on the suitability of biomass production in DWWTSs. 


\subsection{Performance of Individual Treatment Processes}

The breakdown of total embodied and operational burdens of the three stages of treatment processes in each DWWTS is provided in Tables A4 and A5 in Appendix C.

\subsubsection{Primary Settlement Processes}

Septic tanks and settlement tanks in aerated and media-packaged treatment units function as the primary treatment process in conventional and more advanced DWWTSs.

The embodied burdens of the septic tank represented more notable impacts than both packaged treatment process, ranging from 1.82 to 6.01 times greater for $\mathrm{F}$ as 8321 vs. $4565 \mathrm{MJ} /$ p.e. and FE as 0.124 vs. $0.021 \mathrm{~kg}$ P-eq./p.e., respectively. The larger burdens were attributed to the quantity of high-density polyethylene used to produce the septic tank.

The operational impacts of these systems, however, present the opposite results as there is a requirement to desludge the packaged treatment unit more frequently than for the septic tank. As such, the burdens were 4.29 times greater for the packaged systems over the 30-year operational period for all six impact categories (e.g., CC, $455.3 \mathrm{vs.} 106.2 \mathrm{~kg}$ $\mathrm{CO}_{2}$ eq./p.e.). The burdens for desludging are linked to additional transportation of the waste from the site.

The cumulative impacts highlight mixed results as the septic tank presented 1.14-1.36 greater overall burdens than the packaged treatment unit for FE (0.146 vs. $0.115 \mathrm{~kg}$ Peq./p.e.), DW (144.7 vs. $98.7 \mathrm{~m}^{3}$ water eq./p.e.), and MM (7.6E-07 vs. $5.2 \mathrm{E}-07 \mathrm{~kg} \mathrm{Sb}$ eq./p.e.). However, the packaged units present more substantial impacts for the other three categories: 1.32 times greater for $\mathrm{F}(12,997$ vs. $9.861 \mathrm{MJ} /$ p.e.), 1.49 times greater for CC (655.0 vs. $438.6 \mathrm{~kg} \mathrm{CO}_{2}$ eq./p.e.), and 1.96 times greater for $\mathrm{ME}(0.93 \mathrm{vs.} 0.48 \mathrm{~kg} \mathrm{~N}$ eq./p.e.). The cumulative results indicate that the environmental burdens vary across each of the impact categories due to the distinct materials required in its construction and operational demands for desludging.

\subsubsection{Secondary and Tertiary Biological Processes}

As secondary and tertiary treatment processes vary based on site-specific conditions, the results for the different aerated treatment processes (mechanical aeration, soil percolation, sand filtration) that promote further biological treatment of wastewater effluent were compared.

Conventional percolation trenches (either fed by gravity discharge or pumped discharge to raised areas) present more significant embodied burdens for secondary and tertiary treatment, ranging from 1.14-16.14 greater than the other alternative treatment processes (sand filters, LPP pressurised systems, and drip distribution). In these cases, the large quantity of PVC pipework in the conventional percolation areas represented between $42 \%$ and $82 \%$ of each of the six impact categories examined. In addition, the size of the percolation area can be reduced when adopted as a tertiary treatment process as opposed to a secondary process, due to the advanced treatment and effluent quality. The embodied burdens associated with the evapotranspiration stage of treatment (willow bed) was 6.8-9.2 times greater due to the material demands of constructing this treatment process when compared to the raised percolation area (representing the secondary/tertiary process with the greatest burden). This range in amplified environmental burdens represented the following impact categories: F (83,811 vs. 12,410 MJ/p.e.) and DW (2.677 vs. $290 \mathrm{~m}^{3}$ water eq./p.e.).

The results relating to the operational demands of secondary and tertiary effluent treatment showed differences across impact categories and between the conventional and more advanced packaged treatment processes. Drip distribution presented the largest operational burdens of all secondary and tertiary treatment processes in the conventional, packaged, and evapotranspiration systems, ranging from 1.78-3.40 times greater than other processes. The combination of secondary and tertiary treatment was shown in Section 3.2 to have a cumulatively larger burden both for additional material requirements in its construction and due to increased energy demands of pumping between these processes. 
The operational performance of the willow treatment process (ST-W) varies for each impact category. Despite similar CC burdens of $371.3 \mathrm{~kg} \mathrm{CO}_{2}$ eq./p.e. for the willow system and representing comparable results to other secondary and tertiary treatment processes (275.1-995.8 kg CO 2 eq./p.e.), the difference ranged from a net gain 137.4 times greater for ME (0.43 vs. $59.46 \mathrm{~kg} \mathrm{~N}$ eq./p.e.) to a deficit 12.9 times greater for DW (1.941.1 vs. $150.7 \mathrm{~m}^{3}$ water eq./p.e.). This highlighted the complexity of the environmental impacts associated with such a nature-based system. The results highlight the clear value of biomass production to offset embodied carbon and the need for an additional three years to be added to the operational lifespan of the system to fully offset the embodied carbon and its associated CC impacts. However, the system would need to operate for an additional 75 and 109 years than its 30-year design to successfully offset the DW and F burdens, respectively.

\subsection{Uncertainty and Sensitivty Analysis}

\subsubsection{Plastic vs. Concrete Septic/Settlement Tanks}

Given the dominant embodied burdens for many of the impact categories examined (see Figure 2), the impact of different materials used in the manufacturing of these systems was examined. Table 6 provides a comparison of the environmental impacts attributed to plastic and concrete septic tanks, representing uncertainty in the use of a modern or conventional septic tank design, respectively.

Table 6. Comparison of embodied environmental impacts of plastic vs. concrete septic tanks.

\begin{tabular}{|c|c|c|c|c|c|c|}
\hline \multirow[b]{2}{*}{ Septic Tank } & \multirow{2}{*}{$\begin{array}{c}\text { Climate Change } \\
\mathrm{CC} \\
\left(\mathrm{kg} \mathrm{CO} \mathrm{Co}_{2} \text { eq }\right.\end{array}$} & \multicolumn{3}{|c|}{ Ecosystem Quality } & \multicolumn{2}{|c|}{ Resources } \\
\hline & & $\begin{array}{c}\text { FE } \\
\text { (kg P-eq.) }\end{array}$ & $\begin{array}{c}\mathrm{DW} \\
\left(\mathrm{m}^{3} \text { water eq. }\right)\end{array}$ & $\begin{array}{c}\text { ME } \\
\text { (kg N-eq.) }\end{array}$ & $\begin{array}{c}\mathrm{F} \\
(\mathrm{MJ})\end{array}$ & $\begin{array}{c}\text { MM } \\
\text { (kg Sb eq.) }\end{array}$ \\
\hline Plastic & 1.329 .3 & 0.498 & 1.19 & 542.0 & 33,282 & $2.67 \times 10^{-2}$ \\
\hline Concrete & 911.9 & 0.281 & 0.89 & 168.7 & 9.317 & $-4.61 \times 10^{-3}$ \\
\hline
\end{tabular}

The results show that the plastic septic tank has higher environmental burdens across all impact categories, ranging from $25 \%$ to $83 \%$ greater for the ME and MM burdens, respectively. This increase was due to the high environmental impacts of the high-density polyethylene (HDPE) for the plastic septic tank, which presented a $17-82 \%$ greater contribution to the overall burdens as compared to the concrete septic tank. This highlighted the impact of plastic as a material choice in septic tanks, after considering all aspects relating to differences in transportation and installation demands of these products. The replacement of this process unit with a concrete equivalent can reduce the total environmental burden of all six impact categories for the five conventional septic tank systems by a minimum of $4.2-8.1 \%$ for DW and $19.9-30.7 \%$ for F. Less substantial relative improvements were noted for the evapotranspiration system with a maximum improvement across the six impact categories of $12.9 \%$ for CC (104.4 kg CO 2 eq./p.e.).

\subsubsection{Increased Frequency in Desludging of Septic/Settlement Tanks}

The requirement to empty septic tanks every four years or primary settlement tanks in packaged treatment systems annually is an integral operation that ensures the continued performance of these systems. In this case, the impact of reducing the desludging of septic tanks by $10 \%, 25 \%$, or $50 \%$ from the recommended 4 years to a maximum of 2 years, and the settlement tanks in packaged units from 1 year to a maximum of 0.5 years was considered.

A non-linear trend was noted for total environmental impact results as the frequency of desludging increased for each DWTTS, with distinct responses for the conventional, packaged, and willow systems. An increase in the frequency of desludging led to a disproportionate rate of increase in the contribution to the environmental burdens of these DWWTSs for all impact categories. Figure 3 shows the net changes in the total 
environmental impacts for each of the conventional, packaged, and evapotranspiration treatment systems attributed to a $50 \%$ increase in the frequency of desludging.

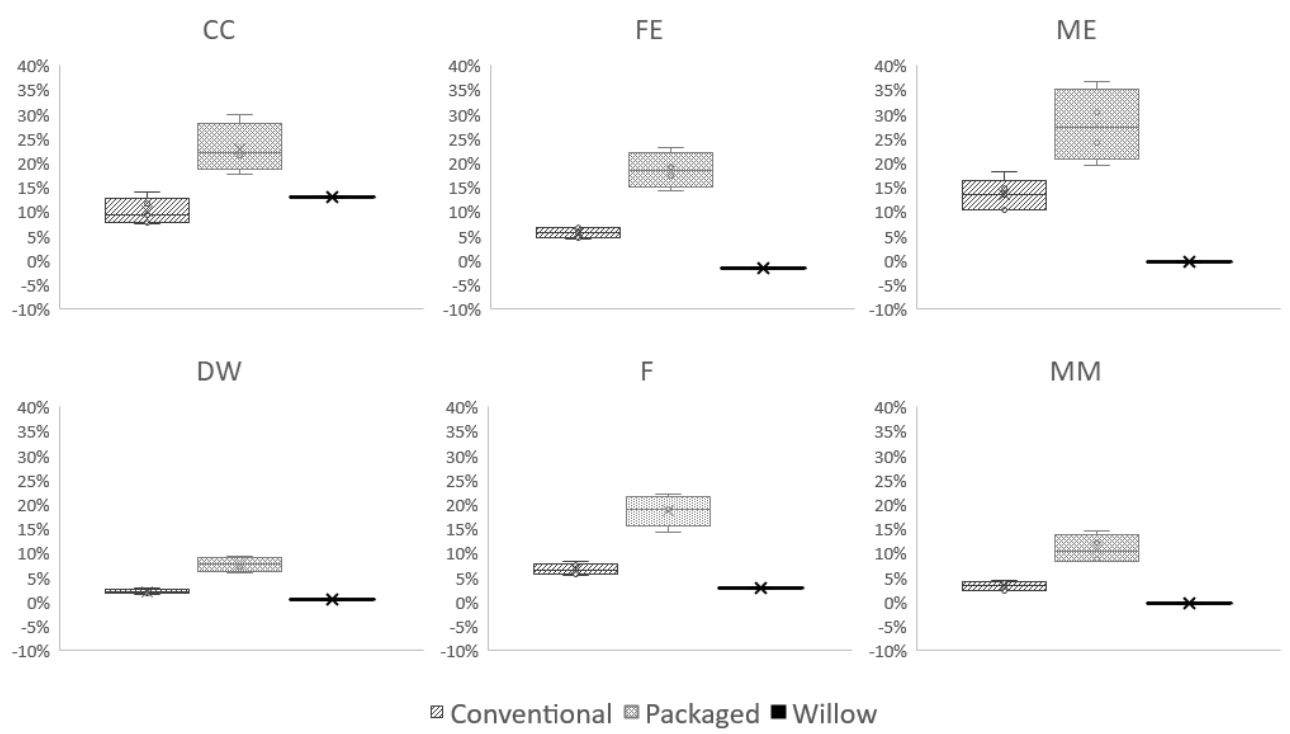

Figure 3. Net change on environmental impacts for each DWWTS for all six impact categories due to $50 \%$ more frequent desludging.

Focusing on the most significant case of a 50\% increase in the frequency of desludging, the most notable increases in total environmental burdens are evident for the packaged treatment systems ranging from $5.9-9.3 \%$ for DW to $19.5-36.8 \%$ for ME. The environmental impacts for the conventional septic tank systems followed a similar trend in relation to the smallest (DW) and largest (ME) increases in burdens, ranging from 1.6-2.9\% and $10.3-18.1 \%$ respectively. Finally, the increased burdens associated with more frequent desludging of the septic tank in the evapotranspiration (ST-W) system equated to $13.0 \%$ for $\mathrm{CC}$, in comparison to very minor changes (a $-1.6 \%$ reduction to a $2.8 \%$ increase) for all other impact categories.

\subsubsection{Reduced Pump Lifespan}

Pumps play an important role in the functioning of many DWWTSs. The demands on these pumps may translate to the 5-year operational lifespan not being attained; therefore, a reduction in the operational lifespan of $10 \%, 25 \%$, and $50 \%$ were examined to understand the environmental impacts on the cumulative burdens of these systems. Reducing the lifespan of the pump by these durations did not produce a linear increase in the associated environmental burdens as the number of pumps required over the 30-year lifespan was disproportionate when considering the $10 \%, 25 \%$, and $50 \%$ reductions in their operational lifespan. However, similar to the desludging results, the rate of increase in the net environmental burdens was greater as more significant reductions in the operational lifespan of the pump were considered.

Examining the net impact of the $50 \%$ reduction in the lifespan of the pump, or 5 years to 2.5 years, the results showed a maximum marginal increase of up to $4.7-7.1 \%$ across five of the six different impact categories, with a more significant maximum increase of $16.7 \%$ for FE. For the evapotranspiration system, the net impact of a reduced lifespan for the pump only accounted for increases up to $2.5 \%$ for most impact categories; yet CC observed an increase of $6.6 \%$.

The findings indicate that any uncertainty relating to the lifespan of the pumps is proportionate to each individual burden for the different DWWTSs. 


\subsubsection{Increased Operational Energy Demands}

The energy demands for pumping and aeration in the different DWWTSs may be unpredictable; therefore, there is a level of uncertainty relating to the operational energy. This assessment considered that the energy demand may be under-estimated by $10 \%, 25 \%$, or $50 \%$ for each treatment system and therefore considered how such an uncertainty might affect the total burdens of these systems.

The environmental burdens were impacted differently for the conventional and packaged treatment systems. The net environmental burdens increase at a faster rate than the percentage increase in operational energy demand for all DWWTSs.

For the most notable under-estimation of 50\%, FE (5.5-8.9\%) and ME (17.1-23.3\%) presented the least- and most-effected impact categories for the conventional treatment systems. The different system configurations after the packaged treatment process presented increases of a minimum of $6.8 \%$ (DW) to $19.8 \%$ (CC) for the PMS-STP system to a maximum of $20.7 \%$ (FE) to $33.7 \%$ (ME) for the packaged treatment systems. The evapotranspiration systems showed a moderate increase of $14.4 \%$ for CC, with all other impact categories presenting negligible increases of less than $4 \%$.

The results suggest that there is a disproportionate impact for different environmental burdens for each DWTTS configurations when potential energy demands may change for each system during its operational life cycle.

\subsubsection{Reduced Biomass Yield from Willow ET Systems}

The yield of biomass influences the environmental performance of the evapotranspiration treatment system; therefore, a reduction of $10 \%, 25 \%$, and $50 \%$ in biomass production was considered to determine its impact on the total burdens of this system. Figure 4 presents the percentage change to the net environmental impacts for the evapotranspiration system when these reductions in biomass (willow) yield were observed.

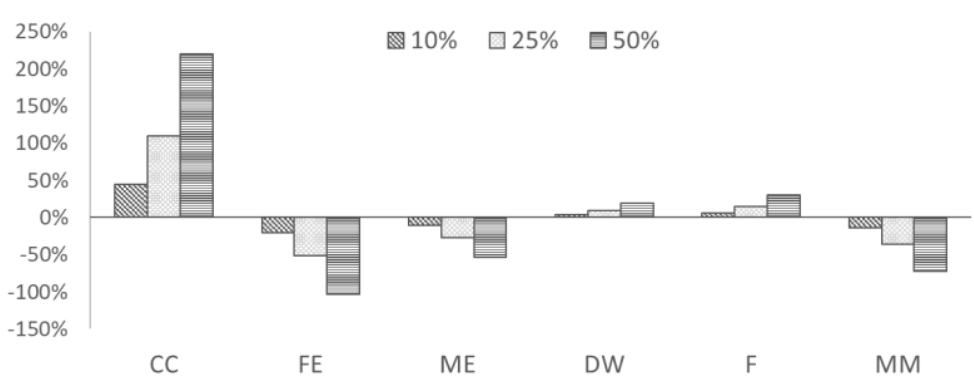

Figure 4. Net change for all impact categories with reduction in biomass yield in evapotranspiration DWWTS.

The results presented in Figure 4 indicate that both proportionate increases and decreases occur for different environmental impact categories due to a reduced yield of biomass. The baseline results found that CC, DW, and MM reported significant environmental impacts, with the FE, ME, and $\mathrm{F}$ burdens presenting net benefits. Considering this, the $10 \%$ and $50 \%$ reductions in biomass production increased the net impacts for CC by $44 \%$ to $220 \%$, for DW by $3.7 \%$ to $18.7 \%$, and for F by $6.0 \%$ to $29.8 \%$.

This equated to a potential extended payback to the net burdens. In the case on ME and $\mathrm{MM}$, the payback remained below the 30-year operational lifespan at a maximum of 4.6 years and 18.7 years, respectively. However, the results indicate that the maximum reduction in biomass yield of 50\% would lead to the payback of the FE burden taking 30.9 years. For the other three impact categories, more substantial paybacks would remain: up to 73.6 years for CC, 160.5 years for F, and 220.1 years for DW.

The results highlight the benefits of biomass production to offset embodied and operational burdens for an evapotranspiration system varying with respect to the impact categories being considered in the assessment. 


\section{Conclusions}

The environmental burdens attributed to different conventional and packaged DWWTSs vary across the range of impact categories assessed based on the configuration of primary, secondary, and tertiary treatment processes.

Despite the environmental burdens being quantified for a 30-year operational lifespan, the results highlight the significant embodied burdens for all DWWTS across each of the six impact categories.

On average, the cumulative burdens for the four packaged treatment systems were very similar (within 3\% for $\mathrm{FE}, \mathrm{DW}$, and $\mathrm{MM}$ ) or significantly higher (between $18 \%$ and $56 \%$ for $\mathrm{CC}, \mathrm{ME}$, and $\mathrm{F}$ ) for each of the six impact categories assessed, as compared to the five more conventional (septic tank based) treatment systems. A closer examination of the results highlighted the increased burdens of between $23 \%$ and $49 \%$ in systems that required three stages of treatment as opposed to two-stage treatment systems. In addition, reducing the requirement of extensive below-ground soil percolation trench construction (e.g., using a low-pressure pipe (LPP) or drip distribution system) or omitting the requirement for pumping presented lower embodied and operational environmental burdens in the different treatment systems, respectively.

The willow evapotranspiration system presented the smallest total burdens of all the DWWTSs for almost all environmental burdens, with three impact categories (FE, $\mathrm{ME}$, and $\mathrm{MM}$ ) demonstrating a net benefit due to the production of biomass during the 30-year operational lifespan of the system. However, the embodied burdens for this system were between 3.0 and 10.8 higher than for all impact categories due to the large-scale construction requirements for such a system (although this was offset from the operational benefits of biomass production in this DWWTS).

The sensitivity and uncertainty analysis highlighted the significant impact of material selection (plastic vs. concrete septic tanks) in a septic/settlement tank with differences ranging from $25-83 \%$, with operational impacts associated with twice-as-frequent desludging leading to increases in the burdens of up to $36.8 \%$. The greatest impact relates to halving the biomass yield in the evapotranspiration system, highlighting a mix of significant environmental deficits (payback of up to 220 years for DW) and gains (payback within 4.60 years for ME) in the environmental impacts over the 30-year operational lifespan considered. An increase in the frequency of desludging, a reduction in the lifespan of pumps, and increased energy demands were shown to have disproportionate impacts on the total environmental burdens for all DWWTS as the percentage change was increased. Doubling the frequency of desludging or increasing the energy demands in these treatment systems increased the ME burden by up to $36.8 \%$ and $33.7 \%$, respectively, whilst halving the pump lifespan had a maximum effect of increasing the FE burden by $16.7 \%$.

The findings of this study indicate that the types of processes adopted, and their configuration (into two or three stages of treatment), can greatly influence the net environmental assessment from a life cycle perspective of a DWWTS. However, it should be appreciated that the design configuration is often dictated by the local site conditions, and so, in practice, the flexibility of the design may be more limited than might be suggested here. Nevertheless, the breakdown of embodied and operational burdens provide clarity on the relative performance of conventional, packaged, and evapotranspiration treatment systems to inform design improvements that can reduce their associated environmental impacts over their life cycle.

Author Contributions: Conceptualization, J.G. and L.W.G.; methodology, J.G.; formal analysis, J.G.; data curation, J.G. and L.W.G.; writing — original draft preparation, J.G.; writing-review and editing, L.W.G. All authors have read and agreed to the published version of the manuscript.

Funding: This research received no external funding.

Institutional Review Board Statement: Not applicable.

Informed Consent Statement: Not applicable. 
Data Availability Statement: Not applicable.

Conflicts of Interest: The authors declare no conflict of interest.

\section{Appendix A}

Table A1. Brief descriptions of different on-site treatment processes in DWWTS (further design details are available and based on the EPA's code of practice [37]).

Treatment Process Description

The tank provides a means of sedimentation through a two-stage or two-chamber system in

Septic tank which the suspended solids are settled out and removed as a primary treatment process.

The $2.6 \mathrm{~m}^{3}$ concrete or plastic (high density polyethylene) tank is installed in the ground to accommodate a gravity flow through the system.

Two-stage aerated systems provide primary and secondary treatment of raw wastewater. A combination of media and mechanical components ensure that aerated conditions are

Aerated/media-packaged systems provided to lower BOD, suspended solids, and ammonium nitrogen concentrations, as well as pathogen reductions (these systems adhere to SR 66 and I.S. EN 12566 Part 3 standards). The media system adopts peat (or an alternative filter material) for wastewater filtration, with a system to distribute the effluent over the bed.

Effluent from a septic tank effluent discharges into a number of percolation pipes in the percolation trenches to distribute the effluent evenly over an area of unsaturated soil. A raised area is adopted when the water table is too high or there is insufficient depth to the bedrock. This leads to an elevated treatment bed with the in-situ soil/subsoil treating the effluent. This may require pumping if insufficient natural gradient is not available. The

Soil percolation trenches/raised percolation area trenches consist of a $110 \mathrm{~mm}$ rigid PVC pipe with holes in it sitting on top of a $300 \mathrm{~mm}$ bed of gravel. The depth to the invert of the percolation trench may vary and is dependent on the required minimum depth of unsaturated soil and/or subsoil beneath the base of the trench gravel and above the bedrock and the water table.

These $60 \mathrm{~m}^{2}$ systems evenly distribute effluents from primary or secondary treatment processes into the infiltration area using a network of small diameter, perforated pipes.

Drip/LPP pressurised system These are placed in shallow, gravel-filled trenches to maximise equally distributed effluent and to promote evapotranspiration from surface vegetation.

The soil-covered or open-sand filter is made up of a monograde sand layer or stratified Sand filter layers of graded sand and a 30-mm washed gravel distribution layer to deliver a flow rate of $30 \mathrm{~L} / \mathrm{m}^{2} /$ day. The filter provides an aerobic environment, and treatment is supported by the development of a biofilm across the small $20 \mathrm{~m}^{2}$ area.

Willow beds or constructed wetlands act as a treatment process by providing evaporation

Evapotranspiration (willow) along the surface and transpiration through the vegetation. They can be used to support treatment in low-permeability soils. However, a large area of $440 \mathrm{~m}^{2}$ is required to allow for effective treatment in low-flow conditions. 
Table A2. Primary inventory data for different on-site DWWTS processes.

\begin{tabular}{|c|c|c|c|c|c|c|c|c|c|c|}
\hline Inventory Item & Unit & Septic Tank & $\begin{array}{l}\text { Packaged } \\
\text { System } \\
\text { (Aerated) }\end{array}$ & $\begin{array}{c}\text { Packaged } \\
\text { System (Media) }\end{array}$ & $\begin{array}{l}\text { Soil Percolation } \\
\text { Trenches }\end{array}$ & $\begin{array}{c}\text { Raised } \\
\text { Percolation } \\
\text { Area }\end{array}$ & $\begin{array}{c}\text { LPP } \\
\text { Pressurised } \\
\text { System }\end{array}$ & Sand Filter & $\begin{array}{c}\text { Drip } \\
\text { Distribution }\end{array}$ & $\begin{array}{c}\text { Evapotranspiration } \\
\text { (Willow) }\end{array}$ \\
\hline JCB excavation & $\mathrm{m}^{3}$ & 30 & 30 & 30 & 10 & 10 & 0.4 & 3.2 & 10 & 300 \\
\hline Concrete tank & $\mathrm{m}^{3}$ & 1.4 & - & - & - & - & - & - & - & - \\
\hline HDPE tank & $\mathrm{kg}$ & 120 & 250 & - & - & - & - & - & - & - \\
\hline Polypropylene media & $\mathrm{kg}$ & - & - & 350 & - & - & - & - & - & - \\
\hline Concrete septic tank (rebar) & $\mathrm{kg}$ & 135 & - & - & - & - & - & - & - & - \\
\hline Concrete anchor for HDP tank & $\mathrm{m}^{3}$ & 0.5 & - & - & - & - & - & - & - & - \\
\hline HPD septic tank & $\mathrm{kg}$ & 120 & - & - & - & - & - & - & - & - \\
\hline Desludging tank & $\mathrm{km}$ & 32 & 32 & 32 & - & - & - & - & - & - \\
\hline Concrete distribution box & $\mathrm{m}^{3}$ & - & - & - & 0.4 & 0.4 & - & - & 0.4 & 0.4 \\
\hline Geotextile (PPE) & $\mathrm{kg}$ & - & - & - & 30.6 & 30.6 & 6.8 & 7.6 & 30.6 & 1.826 \\
\hline Gravel media & $\mathrm{kg}$ & - & - & - & 27,000 & 27,000 & 6.450 & 6.450 & 27,000 & 330,000 \\
\hline PVC piping & $\mathrm{kg}$ & - & - & - & 155.3 & 155.3 & 11 & 6.9 & 155.3 & 262.3 \\
\hline Pump sump (concrete) & $\mathrm{m}^{3}$ & - & - & - & - & 0.6 & 0.6 & 0.6 & 1.6 & 1.6 \\
\hline Submersible pump & $\mathrm{kg}$ & - & 5.0 & 5.0 & - & 5.0 & 5.0 & 5.0 & 5.0 & 5.0 \\
\hline Pumping energy demands & $\mathrm{kWh} / \mathrm{yr}$ & - & 438.0 & 328.5 & - & 109.5 & 109.5 & 109.5 & 328.5 & 109.5 \\
\hline $\begin{array}{l}\text { LPP pipe/distribution manifold } \\
\text { tubing }\end{array}$ & $\mathrm{kg}$ & - & - & - & - & 8.2 & 2.0 & 2.0 & - & - \\
\hline Willow coppicing & $\mathrm{kg}$ & - & - & - & - & - & - & - & - & 7.249 \\
\hline
\end{tabular}




\section{Appendix B}

Table A3. A breakdown of the embodied (E), operational $(\mathrm{O})$ and offset $\left(\mathrm{O}^{*}\right)$ environmental burdens of each primary, secondary and tertiary treatment processes within the 10 on-site DWTTS.

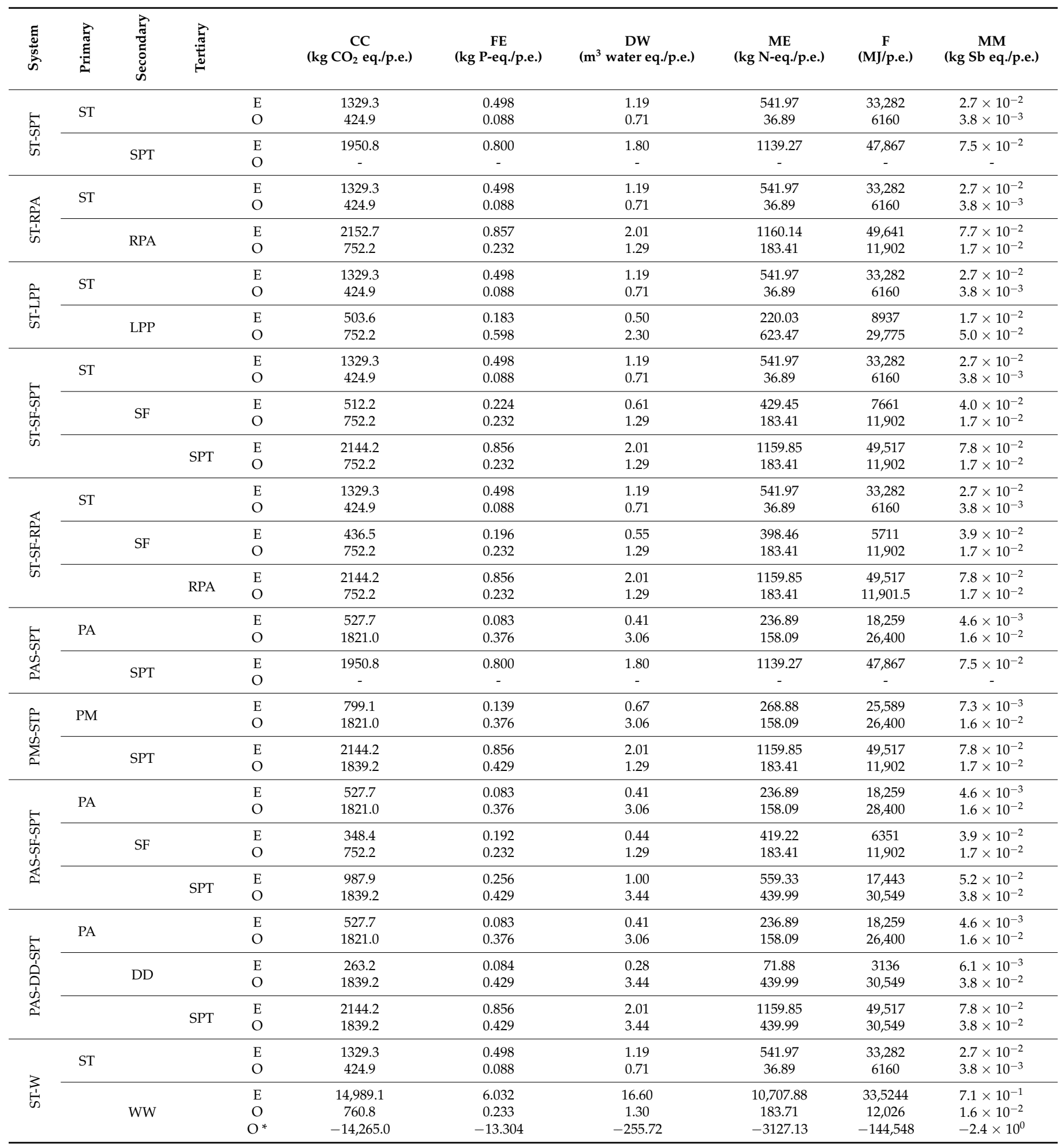




\section{Appendix C}

Table A4. Embodied environmental burdens per population equivalent (p.e.) for each DWTTS.

\begin{tabular}{|c|c|c|c|c|c|c|}
\hline \multirow[b]{2}{*}{ DWWTS } & \multirow{2}{*}{$\begin{array}{c}\text { Climate Change } \\
\mathrm{CC} \\
\text { (kg CO} 2 \text { eq./p.e.) }\end{array}$} & \multicolumn{3}{|c|}{ Ecosystem Quality } & \multicolumn{2}{|c|}{ Resources } \\
\hline & & $\begin{array}{c}\text { FE } \\
\text { (kg P-eq./p.e.) }\end{array}$ & $\begin{array}{c}\mathrm{DW} \\
\left(\mathrm{m}^{3} \text { water eq./p.e. }\right)\end{array}$ & $\begin{array}{c}\text { ME } \\
\text { (kg N-eq./p.e.) }\end{array}$ & $\begin{array}{c}\text { F } \\
(\mathrm{MJ} / \text { p.e. })\end{array}$ & $\begin{array}{c}\text { MM } \\
\text { (kg Sb eq./p.e.) }\end{array}$ \\
\hline (a) ST-SPT & 820.0 & 0.32 & 0.75 & 420.3 & 20,287 & $2.55 \times 10^{-2}$ \\
\hline (b) ST-RPA & 870.5 & 0.34 & 0.80 & 425.5 & 20,731 & $2.60 \times 10^{-2}$ \\
\hline (c) ST-LPP & 458.2 & 0.17 & 0.42 & 190.5 & 10,555 & $1.09 \times 10^{-2}$ \\
\hline (d) ST-SF-SPT & 996.4 & 0.39 & 0.95 & 532.8 & 22,615 & $3.62 \times 10^{-2}$ \\
\hline (e) ST-SF-RPA & 977.5 & 0.39 & 0.94 & 525.1 & 22,127 & $3.58 \times 10^{-2}$ \\
\hline (f) PAS-SPT & 619.6 & 0.22 & 0.55 & 344.0 & 16,531 & $1.99 \times 10^{-2}$ \\
\hline (g) PMS-STP & 735.8 & 0.25 & 0.67 & 357.2 & 18,776 & $2.13 \times 10^{-2}$ \\
\hline (h) PAS-SF-SPT & 466.0 & 0.13 & 0.46 & 303.9 & 10,513 & $2.38 \times 10^{-2}$ \\
\hline (i) PAS-DD-SPT & 733.8 & 0.26 & 0.67 & 367.2 & 17,728 & $2.21 \times 10^{-2}$ \\
\hline (j) ST-W & 4079.6 & 1.63 & 4.45 & 2812.5 & 92,132 & $1.83 \times 10^{-1}$ \\
\hline
\end{tabular}

Table A5. Operational environmental burdens per population equivalent (p.e.) for each DWTTS during its 30-year life cycle.

\begin{tabular}{|c|c|c|c|c|c|c|}
\hline \multirow[b]{2}{*}{ DWWTS } & \multirow{2}{*}{$\begin{array}{c}\text { Climate Change } \\
\mathrm{CC} \\
\text { (kg CO} 2 \text { eq./p.e.) }\end{array}$} & \multicolumn{3}{|c|}{ Ecosystem Quality } & \multicolumn{2}{|c|}{ Resources } \\
\hline & & $\begin{array}{c}\text { FE } \\
(\text { (kg P-eq./p.e.) }\end{array}$ & $\begin{array}{c}\mathrm{DW} \\
\left(\mathrm{m}^{3} \text { water eq./p.e. }\right)\end{array}$ & $\begin{array}{c}\text { ME } \\
\text { (kg N-eq./p.e.) }\end{array}$ & $\begin{array}{c}\text { F } \\
(M J / p . e .)\end{array}$ & $\begin{array}{c}\text { MM } \\
\text { (kg Sb eq./p.e.) }\end{array}$ \\
\hline (a) ST-SPT & 106.2 & 0.02 & 0.18 & 9.2 & 1540 & $9.46 \times 10^{-4}$ \\
\hline (b) ST-RPA & 294.3 & 0.08 & 0.50 & 55.1 & 4515 & $5.17 \times 10^{-3}$ \\
\hline (c) ST-LPP & 294.3 & 0.17 & 0.75 & 165.1 & 8984 & $1.35 \times 10^{-2}$ \\
\hline (d) ST-SF-SPT & 482.3 & 0.14 & 0.83 & 100.9 & 7491 & $9.40 \times 10^{-3}$ \\
\hline (e) ST-SF-RPA & 482.3 & 0.14 & 0.83 & 100.9 & 7491 & $9.40 \times 10^{-3}$ \\
\hline (f) PAS-SPT & 455.3 & 0.09 & 0.76 & 39.5 & 6600 & $4.05 \times 10^{-3}$ \\
\hline (g) PMS-STP & 915.1 & 0.20 & 1.09 & 85.4 & 9575 & $8.28 \times 10^{-3}$ \\
\hline (h) PAS-SF-SPT & 754.1 & 0.19 & 1.36 & 165.1 & 12,153 & $1.48 \times 10^{-2}$ \\
\hline (i) PAS-DD-SPT & 1.025 .8 & 0.24 & 1.90 & 229.2 & 16,815 & $2.02 \times 10^{-2}$ \\
\hline (j) ST-W & -3.269 .8 & -3.25 & -63.43 & -726.6 & $-31,591$ & $-6.00 \times 10^{-1}$ \\
\hline
\end{tabular}

\section{References}

1. EEA. Urban Waste Water Treatment in Europe; European Environment Agency: Luxembourg, 2021.

2. IEA. Water Energy Nexus; International Energy Agency: Paris, France, 2017.

3. EU. Council Directive 91/271/EEC of 21 May 1991 Concerning Urban Waste-Water Treatment; Official Journal of the European Community: Luxembourg, 1991.

4. Arora, M.; Malano, H.; Davidson, B.; Nelson, R.; George, B. Interactions between centralized and decentralized water systems in urban context: A review. WIREs Water 2015, 2, 623-634. [CrossRef]

5. Coutard, O.; Rutherford, J. Beyond the Networked City: Infrastructure Reconfigurations and Urban Change in the North and South, 1st ed.; Routledge: London, UK, 2015.

6. Eggimann, S.; Truffer, B.; Maurer, M. Economies of density for on-site waste water treatment. Water Res. 2016, 101, 476-489. [CrossRef] [PubMed]

7. Obertreis, J.; Moss, T.; Mollinga, P.P.; Bichsel, C. Water, infrastructure and political rule. Water Altern. 2016, 9. [CrossRef]

8. Capodaglio, A.G.; Callegari, A.; Cecconet, D.; Molognoni, D. Sustainability of decentralized wastewater treatment technologies. Water Pract. Technol. 2017, 12, 463-477. [CrossRef]

9. Hacker, M.E.; Binz, C. Institutional Barriers to On-Site Alternative Water Systems: A Conceptual Framework and Systematic Analysis of the Literature. Environ. Sci. Technol. 2021, 55, 8267-8277. [CrossRef] [PubMed]

10. Zang, J.; Kumar, M.; Werner, D. Real-world sustainability analysis of an innovative decentralized water system with rainwater harvesting and wastewater reclamation. J. Environ. Manag. 2021, 280, 111639. [CrossRef]

11. Parkinson, J.; Tayler, K. Decentralized wastewater management in peri-urban areas in low-income countries. Environ. Urban. 2003, 15, 75-90. [CrossRef]

12. Chirisa, I.; Bandauko, E.; Matamanda, A.; Mandisvika, G. Decentralized domestic wastewater systems in developing countries: The case study of Harare (Zimbabwe). Appl. Water Sci. 2017, 7, 1069-1078. [CrossRef]

13. CSO. Census 2016, Principal Demographic Results; Central Statistics Office: New Delhi, India, 2016. 
14. Hawkins, P.; Blackett, I.; Heymans, C. The missing link in sanitation service delivery. A review of fecal sludge management in 12 Cities. In Research Brief; WSP: Washington, DC, USA, 2014.

15. Gill, L.W.; O'Súlleabháin, C.; Misstear, B.D.R.; Johnston, P.J. The Treatment Performance of Different Subsoils in Ireland Receiving On-Site Wastewater Effluent. J. Environ. Qual. 2007, 36, 1843-1855. [CrossRef]

16. Gill, L.W.; O'luanaigh, N.; Johnston, P.M.; Misstear, B.D.R.; O'suilleabhain, C. Nutrient loading on subsoils from on-site wastewater effluent, comparing septic tank and secondary treatment systems. Water Res. 2009, 43, 2739-2749. [CrossRef]

17. Keegan, M.; Kilroy, K.; Nolan, D.; Dubber, D.; Johnston, P.M.; Misstear, B.D.; O'Flaherty, V.; Barrett, M.; Gill, L.W. Assessment of the impact of traditional septic tank soakaway systems on water quality in Ireland. Water Sci. Technol. 2014, 70, 634-641. [CrossRef] [PubMed]

18. O'Luanaigh, N.D.; Goodhue, R.; Gill, L.W. Nutrient removal from on-site domestic wastewater in horizontal subsurface flow reed beds in Ireland. Ecol. Eng. 2010, 36, 1266-1276. [CrossRef]

19. Gill, L.W.; O'Súlleabháin, C.; Misstear, B.D.; Johnston, P.M. Comparison of Stratified Sand Filters and Percolation Trenches for On-Site Wastewater Treatment. J. Environ. Eng. 2009, 135, 8-16. [CrossRef]

20. Curneen, S.; Gill, L. Upflow Evapotranspiration System for the Treatment of On-Site Wastewater Effluent. Water 2015, 7, 2037-2059. [CrossRef]

21. Devereux, C.; Coscia, J.; Adeyeye, K.; Gallagher, J. Energy security to safeguard community water services in rural Ireland: Opportunities and challenges for solar photovoltaics. Sustain. Energy Technol. Assess. 2021, 47, 101377.

22. Shahabi, M.P.; McHugh, A.; Anda, M.; Ho, G. Comparative economic and environmental assessments of centralised and decentralised seawater desalination options. Desalination 2015, 376, 25-34. [CrossRef]

23. Dubber, D.; Gill, L. Application of On-Site Wastewater Treatment in Ireland and Perspectives on Its Sustainability. Sustainability 2014, 6, 1623-1642. [CrossRef]

24. Bradley, B.R.; Daigger, G.T.; Rubin, R.; Tchobanoglous, G. Evaluation of onsite wastewater treatment technologies using sustainable development criteria. Clean Technol. Environ. Policy 2002, 4, 87-99. [CrossRef]

25. Corominas, L.; Byrne, D.M.; Guest, J.S.; Hospido, A.; Roux, P.; Shaw, A.; Short, M.D. The application of life cycle assessment (LCA) to wastewater treatment: A best practice guide and critical review. Water Res. 2020, 184, 116058. [CrossRef]

26. Zawartka, P.; Burchart-Korol, D.; Blaut, A. Model of Carbon Footprint Assessment for the Life Cycle of the System of Wastewater Collection, Transport and Treatment. Sci. Rep. 2020, 10, 5799. [CrossRef] [PubMed]

27. Tillman, A.-M.; Lundström, M.S.H. Life cycle assessment of municipal waste water systems. Int. J. Life Cycle Assess. 1998, 3, 145-157. [CrossRef]

28. Niero, M.; Pizzol, M.; Bruun, H.G.; Thomsen, M. Comparative life cycle assessment of wastewater treatment in Denmark including sensitivity and uncertainty analysis. J. Clean. Prod. 2014, 68, 25-35. [CrossRef]

29. McNamara, G.; Fitzsimons, L.; Horrigan, M.; Phelan, T.; Delaure, Y.; Corcoran, B.; Clifford, E. Life cycle assessment of waste water treatment plants in Ireland. In South East European Conference on Sustainable Development of Energy; Water and Environment Systems: Ohrid, North Macedonia, 2014.

30. Nogueira, R.; Brito, A.G.; Machado, A.P.; Janknecht, P.; Salas, J.J.; Vera, L.; Martel, G. Economic and environmental assessment of small and decentralized wastewater treatment systems. Desalin. Water Treat. 2009, 4, 16-21. [CrossRef]

31. Raghuvanshi, S.; Bhakar, V.; Sowmya, C.; Sangwan, K.S. Waste Water Treatment Plant Life Cycle Assessment: Treatment Process to Reuse of Water. Procedia CIRP 2017, 61, 761-766. [CrossRef]

32. Singh, A.; Sawant, M.; Kamble, S.J.; Herlekar, M.; Starkl, M.; Aymerich, E.; Kazmi, A. Performance evaluation of a decentralized wastewater treatment system in India. Environ. Sci. Pollut. Res. 2019, 26, 21172-21188. [CrossRef] [PubMed]

33. Fuchs, V.J.; Mihelcic, J.R.; Gierke, J.S. Life cycle assessment of vertical and horizontal flow constructed wetlands for wastewater treatment considering nitrogen and carbon greenhouse gas emissions. Water Res. 2011, 45, 2073-2081. [CrossRef] [PubMed]

34. ISO. ISO 14040: Environmental Management_Life Cycle Assessment_Principles and Framework; ISO: Geneva, Switzerland, 2006.

35. ISO. ISO 14044: Environmental Management_Life Cycle Assessment_Requirements and Guidelines; ISO: Geneva, Switzerland, 2006.

36. Kalbar, P.P.; Karmakar, S.; Asolekar, S.R. Assessment of wastewater treatment technologies: Life cycle approach. Water Environ. J. 2013, 27, 261-268. [CrossRef]

37. EPA. Code of Practice for Domestic Waste Water Treatment Systems (Population Equivalent $\leq 10$ ); Environmental Protection Agency: Washington, DC, USA, 2021.

38. Fernández-Baca, C.P.; Omar, A.E.; Reid, M.C.; Richardson, R.E. Temporal Lags in Post-Rain Greenhouse Gas Cycling and Fluxes from Septic Leach Field Soils and Associated Greenhouse Gas Cycling Microbial Populations. J. Sustain. Water Built Environ. 2020, 6, 04020004. [CrossRef]

39. Somlai, C.; Knappe, J.; Gill, L. Spatial and temporal variation of $\mathrm{CO}_{2}$ and $\mathrm{CH}_{4}$ emissions from a septic tank soakaway. Sci. Total. Environ. 2019, 679, 185-195. [CrossRef]

40. Curneen, S.; Gill, L.W. Willow-based evapotranspiration systems for on-site wastewater effluent in areas of low permeability subsoils. Ecol. Eng. 2016, 92, 199-209. [CrossRef]

41. Ecoinvent. Ecoinvent 3.6 (2019) Database; 2020; Available online: https:/ / ecoquery.ecoinvent.org/ (accessed on 20 June 2020).

42. Wolf, M.-A.; Chomkhamsri, K.; Pant, R. International Reference Life Cycle Data System (ILCD) Handbook-Towards More Sustainable Production and Consumption for a Resource-Efficient Europe; Publications Office of the European Union: Luxembourg, 2012. 
43. Gill, L.W.; Mahon, J.M.; Knappe, J.; Gharbia, S.; Pilla, F. Desludging rates and mechanisms for domestic wastewater treatment system sludges in Ireland. In STRIVE Report Series No. 253; Environmental Protection Agency: Wexford, Ireland, 2018 ; p. 24.

44. Gallagher, J.; Basu, B.; Browne, M.; Kenna, A.; McCormack, S.; Pilla, F.; Styles, D. Adapting Stand-Alone Renewable Energy Technologies for the Circular Economy through Eco-Design and Recycling. J. Ind. Ecol. 2019, 23, 133-140. [CrossRef] 